\title{
Gastric endoscopic submucosal dissection using the "pulley clip with elastic line" method
}
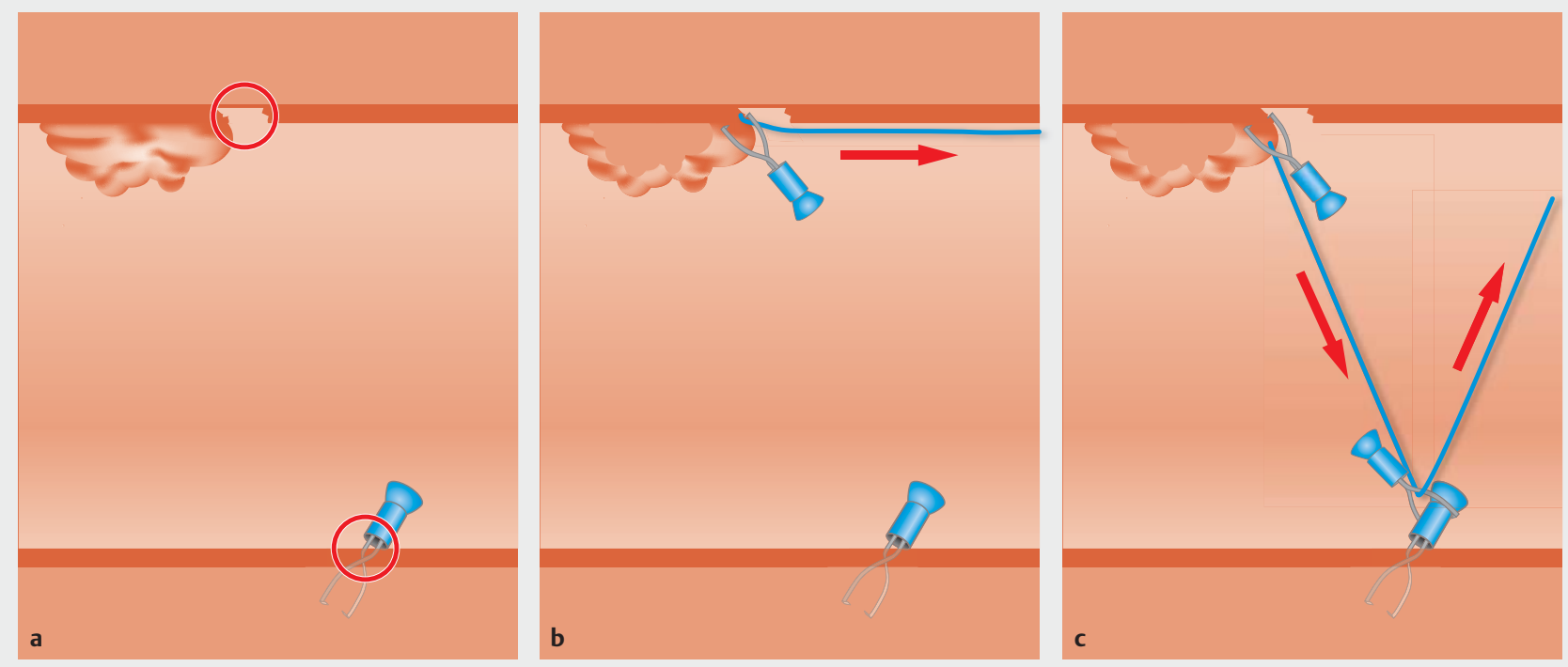

- Fig. 1 Schema of clip attachment in the "pulley clip with elastic line" method. a The normal mucosal border and direction in which the lesion is to be pulled are determined, and a clip is attached to the contralateral normal gastric mucosa. $\mathbf{b}$ A clip is attached to a suitable site on the lesion. c By attaching a clip-on-clip, the middle clip plays the role of a pulley and the lesion can be pulled continuously.

Visibility of the submucosa is important for safe and quick gastric endoscopic submucosal dissection (ESD) [1 -4]. Thus, we have developed a new efficient traction method called the "pulley clip with elastic line" method (PEM).

A commercially available elastic line (elastic synthetic fiber with a diameter of $0.5 \mathrm{~mm}$ ), hemostatic clip (HX-610-090S/ HX-610-090L; Olympus, Tokyo, Japan), and hemoclip applicator device (HX110QR; Olympus) are used (\Video 1). First, an incision is made around the lesion, as in normal ESD. The normal mucosal border and direction in which the lesion is to be pulled are determined. A clip is attached to the contralateral normal gastric mucosa on the tow direction line ( $\triangleright$ Fig. 1 a). The endoscope is withdrawn. Then, a hemoclip applicator device is inserted into the accessory channel of the endoscope, and a hemoclip is mounted onto the tip of the clip device. A length of elastic line is tied directly to the stainless steel ribbon of the clip so that the elastic
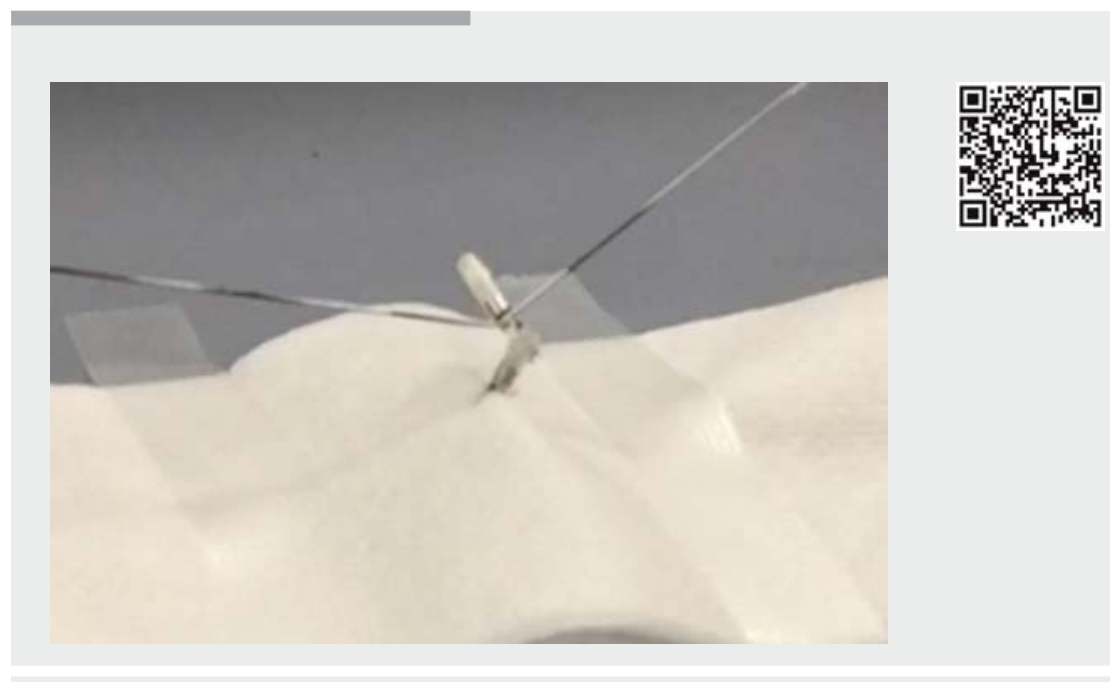

Video 1 The "pulley clip with elastic line" method and its use in gastric endoscopic submucosal dissection.

line clip assembly is contained in the channel of the scope. After reinsertion of the scope into the stomach, a clip is attached to a suitable site on the lesion for oral or anal traction ( $\mathbf{F i g . 1} \mathbf{b}$ ). When a clip-on-clip attachment is performed, as shown in - Video 1 , the middle clip plays the role of a pulley, and the lesion 


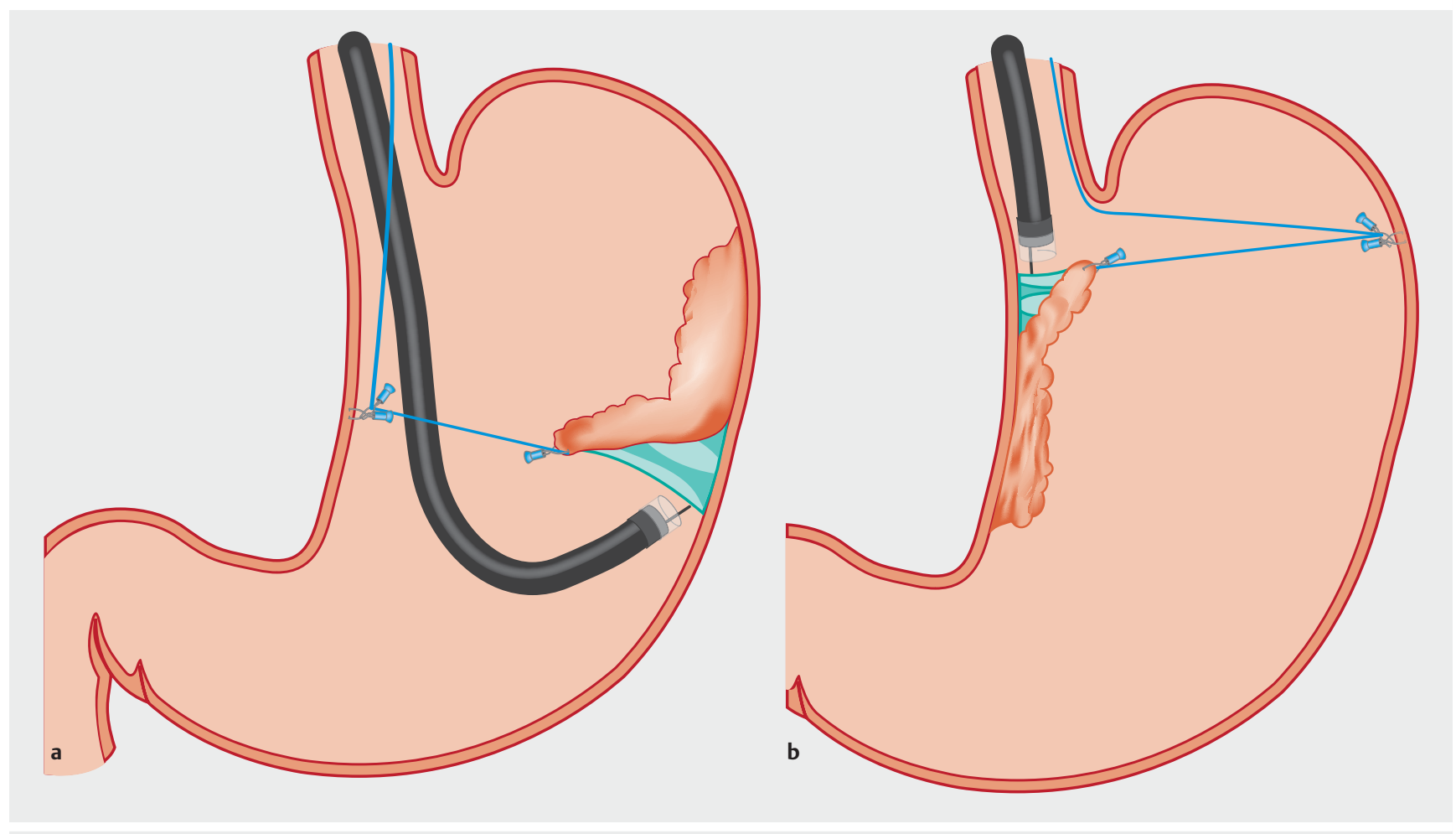

- Fig. 2 Schema of gastric endoscopic submucosal dissection using the "pulley clip with elastic line" method.

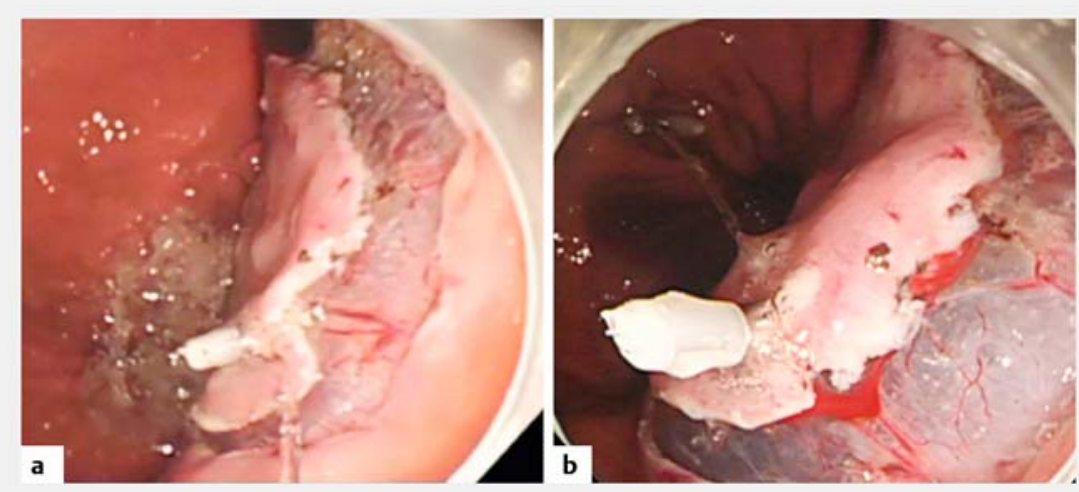

- Fig. 3 Endoscopic view. a The gastric lesion at the lesser curvature wall in the middle gastric body before "pulley clip with elastic line" method (PEM) administration; effective traction is not achieved. $\mathbf{b}$ The same lesion after PEM administration; effective traction is achieved.

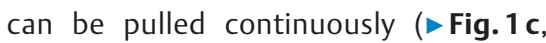
> Fig. 2, > Fig.3). Furthermore, use of an elastic line prevents the lesion from being torn due to excessive traction.

- Video 1 shows an example of gastric ESD using PEM. When PEM is performed, visualization of the submucosal layer is continuous and finding a hemostasis point becomes easy. In addition, the visual field can be obtained in the forward and retroflex positions. The lesions were completely removed with free margins. In summary, "PEM" is useful for performing gastric ESD safely and easily.

Endoscopy_UCTN_Code_TTT_1AO_2AG
Competing interests

None

The authors

Tatsuma Nomura, ${ }^{1,2}$, Akira Kamei ${ }^{2}$, Shinya Sugimoto ${ }^{2}$

1 Department of Gastroenterology, Kinan Hospital, Minamimuro, Japan

2 Department of Gastroenterology, Ise Red Cross Hospital, Ise, Japan

\section{Corresponding author}

\section{Tatsuma Nomura, MD}

Department of Gastroenterology, Kinan Hospital, 4750 Atawa, Mihama-cho,

Minamimuro-gun, Mie 519-5293, Japan Fax: +81-05979-2-3357 m06076tn@icloud.com 


\section{References}

[1] Kobayashi T, Gotohda T, Tamakawa K et al. Magnetic anchor for more effective endoscopic mucosal resection. Jpn J Clin Oncol 2004; 34: $118-123$

[2] von Delius S, Karagianni A, von Weyhern $\mathrm{CH}$ et al. Percutaneously assisted endoscopic surgery using a new PEG-minitrocar for advanced endoscopic submucosal dissection (with videos). Gastrointest Endosc 2008; 68 : 365-369

[3] Motohashi O, Nishimura K, Nakayama N et al. Endoscopic submucosal dissection (twopoint fixed ESD) for early esophageal cancer. Dig Endosc 2009; 21: 176 -179
[4] Aihara H, Kumar N, Ryou M et al. Facilitating endoscopic submucosal dissection: the suture-pulley method significantly improves procedure time and minimizes technical difficulty compared with conventional technique: an ex vivo study (with video). Gastrointest Endosc 2014; 80: 495-502

\section{Bibliography}

DOI https://doi.org/10.1055/s-0043-125358

Published online: 2.2.2018

Endoscopy 2018; 50: E104-E106

(c) Georg Thieme Verlag KG

Stuttgart · New York

ISSN 0013-726X

\section{ENDOSCOPY E-VIDEOS}

https://eref.thieme.de/e-videos

回回 Endoscopy E-Videos is a free access online section, reporting 国: on interesting cases and new techniques in gastroenterological endoscopy. All papers include a high quality video and all contributions are freely accessible online.

This section has its own submission website at

https://mc.manuscriptcentral.com/e-videos 